\title{
MOTOR AND FUNCTIONAL ABILITIES OF U-19 ELITE CROATIAN SOCCER PLAYERS
}

\author{
Željko Kovačević́, Lovro Štefan ${ }^{2}$, Goran Sporiš² ${ }^{2}$, Duje Poljak ${ }^{3}$, Rasa Kreivyte் \\ University of Split ${ }^{1}$, Split, Croatia \\ University of Zagreb ${ }^{2}$, Zagreb, Croatia \\ Football club "Hajduk", Split, Croatia \\ Lithuanian Sports University ${ }^{4}$, Kaunas, Lithuania
}

\begin{abstract}
Background. Soccer is known as one of the most popular games in the world. Because of constant profiling and improving, players and their conditioning abilities need to be on top level to achieve great sport results. The aim of this study was to determine conditioning profile of junior players playing on different playing positions.

Methods. Sample of 85 junior elite soccer players (17.06 \pm 0.74 years) was included in the study (height: $1.75 \pm$ $0.05 \mathrm{~m}$; weight: $73.59 \pm 9.56 \mathrm{~kg}$; body mass index: $\left.23.97 \pm 0.45 \mathrm{~kg} / \mathrm{cm}^{2}\right)$. Sample of variables consisted of five motor ability tests (standing long jump-SLJ, high jump-HJ, $30 \mathrm{~m}$ sprint-SP30M, $60 \mathrm{~m}$ sprint-SP60M, $5 \mathrm{x} 10 \mathrm{~m}$ sprint-SP5 x $10 \mathrm{M})$ and one functional ability test $(1500 \mathrm{~m}$ run-R1500M). To determine significant differences among players playing on different playing positions and to establish where those differences were, one-way ANOVA with Scheffe post-hoc test were used. For better understanding, which tests distinguish each position the most, discriminant analysis was performed.

Results. Results showed that the sample which consisted of five groups (defenders, goalkeepers, attackers, stoppers and midfielders), significantly differed in variable SLJ $(p=.00)$. Scheffe post-hoc test significant differences between defenders and goalkeepers $(p=.01)$, goalkeepers and stoppers $(p=.00)$ and goalkeepers and midfielders $(p=.01)$.

Conclusions. Results clearly represented homogenous collective, where players, no matter which position they were, had similar values in obtained tests. The explanation of obtained results could be found in similar preparedness and great sports form, which must be on optimal level for best performance.
\end{abstract}

Keywords: motor abilities, functional abilities, preparedness.

\section{INTRODUCTION}

$\mathrm{S}$ occer is one of the most-played sports in the world (Bangsbo, 1994b). It is played by women, children and adults at different levels of training (Janjić, Suzović, \& Janković, 2010). Common characteristics are that these are team sports with intermittent high-intensity activities (Barbero-Alvarez, Soto, Barbero-Alvarez, \& Granda-Vera, 2008; Bangsbo, Norregaarg, \& Thorso, 1991; Ben Abdelkrim, El Fazza, \& El Ati, 2007). According to Bangsbo (1994a), for successful performance of specific tasks during games, athletes must possess appropriate abilities.
Abilities of the players are classified into four groups: technical, tactical, psychosocial and motor. In soccer, motor skills are built upon aerobic and anaerobic capacity, speed, agility, and muscle strength (Bangsbo, Mohr, \& Krustrup, 2006). Kutlu, Yapıc1, Yoncalık, and Celik (2012) reported that motor skills such as acceleration, deceleration, and the ability to change direction during maximal effort were crucial. Based on that, the main task of all programs is improvement of trainings and results, improvement of general, targeted and specific abilities and characteristics that are 
essential for successful participation in training and competition activities (Janjić et al., 2010). Team of experts led by coaches believe that success on the field is associated with anthropometric characteristics of players (Brahim, Bougatfa, \& Mohamed, 2013). Some previous studies have shown the relationship between anthropometric profile of the players and their standing positions (Rienzi, Drust, Reilly, Carter, \& Martin, 2000; Gil, Ruiz, Irazusta, \& Irazusta, 2007). Because of that, the aim of the study was to determine whether there were significant differences in motor and functional tests among junior elite soccer players playing on different playing positions.

\section{METHODS}

Participants. The sample consisted of eightyfive junior elite soccer players (age: $17.06 \pm 0.74$ years; height: $1.75 \pm 0.05 \mathrm{~m}$; weight: $73.59 \pm$ $9.56 \mathrm{~kg}$; body mass index: $23.97 \pm 0.45 \mathrm{~kg} / \mathrm{cm}^{2}$ ) playing in Croatian First League. Players differed according to their standing positions on the field and, based on that, had different values in motor and functional ability tests in the group. All testing procedures were carried out following the principles of the Helsinki Declaration and with the permission of their parents/guardians. There were seven defenders and goalkeepers, fourteen attackers, twenty-nine midfielders and twentyeight stoppers.

Procedures. The sample of variables consisted of five motor ability tests (standing long jumpSLJ, high jump-HJ, $30 \mathrm{~m}$ sprint-SP30M, $60 \mathrm{~m}$ sprint-SP60M, 5 x $10 \mathrm{~m}$ sprint-SP5 x 10M), and one functional ability test $(1500 \mathrm{~m}$ run-R1500M). The measuring part took place in the morning (between 9-11 a. m.), before that participants had their morning breakfast and good night sleep. Also, participant did not participate in matches later that one day and wore soccer shoes, white socks, blue shorts, white T-shirts. Before testing, every player did a 10-minute warm-up and stretch training. The temperature was $23^{\circ} \mathrm{C}$. The height of the participant was measured using anthropometry (at the Faculty of Kinesiology, University of Split).

Weight was also measured using digital scale with a precision to the nearest of $0.1 \mathrm{~kg}$. Body mass index (BMI) was calculated using general formula: $\mathrm{BMI}=$ height $[\mathrm{kg}] /$ weight $\left[\mathrm{m}^{2}\right]$. Standing long jump was measured using a tape measure affixed to the floor. Specific instructions were given to the players to begin the jump with flexed knees and arm swing was allowed to assist the jump. If the player fell backward, the nearest body part from the start line to touch the ground was used to measure the distance of the jump. The best of three jumps was used for analysis (Almuzaini \& Fleck, 2008).

Height jump was measured using Quattro Jump (Kistler, Switzerland, 2008). Each player attempted to jump as high as possible. Each player performed three jumps with two minutes rest between jumps. The highest jump was selected for analysis (Almuzaini \& Fleck, 2008). Each participant swung with the arms to help the body got better vertical force.

Sprint over 30 and $60 \mathrm{~m}$ was measured using infrared photocells, where participant accelerated from the beginning to the end and times were recorded on the $30^{\text {th }}$ and $60^{\text {th }} \mathrm{m}$. The test was performed three times and the best score was used for the analysis. The rest between each series was two minutes.

$5 \times 10 \mathrm{~m}$ test outcomes were assessed using cones which were put 10 meters from each other. Participant had to run as fast as possible from one to the other cone 5 times. Test was measured three times and the best score was used for the analysis. The rest between each series was three minutes.

$1500 \mathrm{~m}$ run results were assessed using athletic track, where one lap was $400 \mathrm{~m}$ in length. We calculated them for $1500 \mathrm{~m}$ and participants needed to run as fast as possible to cover the agreed distance. The test was performed only once.

Data analysis. Kolmogorov-Smirnov test was used to determine if distributions were normal. Also, descriptive statistics (arithmetic mean, standard deviation) was used for basic information about the participants. To determine significant differences between each playing position, one-way analysis of variance (ANOVA) was used. When significant differences were obtained, Scheffe posthoc test was used to see among which groups those differences occurred. Statistical significance was set at $p<.05$.

\section{RESULTS}

Kolmogorov-Smirnov test showed that variables were normally distributed. Results in Table 1 showed basic descriptive statistics in each group of players according to their playing positions on the field and differences between each group. Results represented statistically significant differences in 
Table 1. Descriptive parameters and significant differences between group (mean \pm standard deviations)

\begin{tabular}{|c|c|c|c|c|c|c|}
\hline Variables & $\begin{array}{c}\text { Defenders } \\
(n=7)\end{array}$ & $\begin{array}{c}\text { Goalkeepers } \\
(n=7)\end{array}$ & $\begin{array}{c}\text { Attackers } \\
(n=\mathbf{1 4})\end{array}$ & $\begin{array}{c}\text { Midfielders } \\
(n=\mathbf{2 8})\end{array}$ & $\begin{array}{c}\text { Stoppers } \\
(n=\mathbf{2 9})\end{array}$ \\
\hline SLJ (m) & $2.48 \pm 0.06^{*}$ & $2.72 \pm 0.11^{* \# *}$ & $2.56 \pm 0.10$ & $2.53 \pm 0.11^{*}$ & $2.50 \pm 0.13^{\#}$ & .000 \\
\hline HJ (m) & $0.53 \pm 0.05$ & $0.60 \pm 0.07$ & $0.57 \pm 0.04$ & $0.56 \pm 0.05$ & $0.55 \pm 0.05$ & $\mathrm{n} . \mathrm{s}$ \\
\hline SP30M (s) & $4.23 \pm 0.15$ & $4.24 \pm 0.11$ & $4.20 \pm 0.09$ & $4.28 \pm 0.15$ & $4.26 \pm 0.13$ & $\mathrm{n} . \mathrm{s}$ \\
\hline SP60M (s) & $7.57 \pm 0.23$ & $7.65 \pm 0.19$ & $7.57 \pm 0.16$ & $7.75 \pm 0.26$ & $7.71 \pm 0.27$ & $\mathrm{n} . \mathrm{s}$ \\
\hline SP5x10m (s) & $10.74 \pm 0.25$ & $11.04 \pm 0.70$ & $10.71 \pm 0.23$ & $10.85 \pm 0.32$ & $10.92 \pm 0.24$ & $\mathrm{n} . \mathrm{s}$ \\
\hline R1500M (s) & $292.2 \pm 18.0$ & $294.6 \pm 13.8$ & $303.6 \pm 16.2$ & $300.0 \pm 18.0$ & $300.0 \pm 21.6$ & $\mathrm{n} . \mathrm{s}$ \\
\hline
\end{tabular}

Note. $* p<.05$ between defenders and goalkeepers,

${ }^{\#} p<.05$ between goalkeepers and stoppers,

$" p<.05$ between goalkeepers and midfielders.

Table 2. Significant discriminant root and $p$-value

\begin{tabular}{|c|c|c|c|c|c|}
\hline Root & Eigenvalue & Canonical R & Wilks' lambda & Chi-Sqr. & $p$ \\
\hline 1 & 0.74 & 0.65 & 0.46 & 60.79 & $\mathbf{. 0 0}$ \\
\hline
\end{tabular}

Note. $p<.05$.

standing long jump test between each group of players $(p=.00)$. According to Scheffe post-hoc test, significant differences were found between defenders and goalkeepers $(p=.01)$, goalkeepers and stoppers $(p=.00)$ and goalkeepers and midfielders $(p=.01)$. Other variables did not show statistically significant differences between groups.

In Table 2, discriminant analysis showed that only the first root was significant $(p<.001)$, while in Table 3, results showed that variable SLJ differed in all five groups (defenders to stoppers) on the highest level $(-1.00)$, SP60M $(-0.91)$ and SP5 x $10 \mathrm{~m}(-0.90)$.

Table 3. Standardized coefficients for canonical variables

\begin{tabular}{|c|c|}
\hline Variables & Root 1 \\
\hline SLJ $(\mathrm{m})$ & -1.00 \\
\hline HJ $(\mathrm{m})$ & -0.44 \\
\hline SP30M (s) & 0.58 \\
\hline SP60M (s) & -0.91 \\
\hline SP5x10m (s) & -0.90 \\
\hline R1500M (s) & 0.28 \\
\hline Cum. Prop. & 0.76 \\
\hline
\end{tabular}

\section{DISCUSSION}

The aim of the study was to determine motor and functional test values between junior soccer players playing in different playing positions on the field and use these factors to conduct discriminant analysis to explore predictive ability of these factors. Also, we wanted to determine significant differences between each of the tests among players and their role on the field. Our results showed that there were statistical differences in variable SLJ between defenders and goalkeepers $(p<.05 ;+9.6 \%$ better result for goalkeepers), goalkeepers and stoppers $(p<.05 ;+8.8 \%$ better result for goalkeepers) and goalkeepers and midfielders $(p<.05 ;+7.3 \%$ better results for goalkeepers). Zalai et al. (2015) reported no statistical differences between each playing position in the same variable $(p=.51)$. In their study, defenders had the highest result followed by midfielders. Our results were similar to other studies where there were no statistical difference in jump height between goalkeepers, defenders, midfielders and forwards (Zalai et al., 2015; Gil et al., 2007; Malina et al., 2000; Adhikari \& Kumar, 1993; Rocha, 1975), but goalkeepers showed the highest results, except for the study of Zalai et al. (2015), where they had the lowest result. According to Malina, Cumming Morano, Barron, and Miller (2005), attackers had the highest scores in $30 \mathrm{~m}$ sprint, followed by defenders. Pivovarniček, Pupiš, Tonhauzerova, and Tokarova (2014) also showed that attackers had the best time in $30 \mathrm{~m}$ sprint, followed by midfielders ( $4.56 \pm 0.10 \mathrm{~s})$, defenders $(4.67 \pm 0.07 \mathrm{~s})$ and goalkeepers $(4.72 \pm 0.04 \mathrm{~s})$. Zalai et al. (2015) reported that defenders had the best result in $30 \mathrm{~m}$ sprint $(4.27 \pm 0.10 \mathrm{~s})$, followed by midfielders $(4.36 \pm 0.12 \mathrm{~s})$ and attackers $(4.37 \pm$ $0.24 \mathrm{~s}$ ). According to Karavelioglu (2008), stoppers were the slowest group in 60 meter sprint, while attackers were the fastest, which our study also showed. Sporiš, Ružić, \& Leko (2008) reported that mean value from three trials was around $8 \mathrm{sec}$ 
from the group independent on the playing position. Obtained results in 1500 meter run showed that defenders had best results, probably because of aerobic endurance, which need to be on a higher level, opposed to attackers, whose anaerobic capacities are well-trained for short distance covered and different situational efficiency on the field. Iorsac (2009) reported that 18-year-old soccer players had average values in agility $5 \times 10 \mathrm{~m}$ test between $10.5-11 \mathrm{~s}$, which was very similar to our results, although the author did not differentiate players according to playing positions on the field. From the obtained results of discriminant analysis and based on Table 1, where only values from SLJ represented statistical differences among groups, it could be seen that this variable differentiated groups the most, followed by SP60M $(-0.91)$ and SP5 x 10m (-0.90). Discriminant values showed that players, especially goalkeepers, needed to have great explosive power of lower limbs because of the ability of catching the ball, kicking the ball and going on the ball during the game. Also, attackers needed to have great sprinting performance on 30 $\mathrm{m}$ sprint to gain the advantage over the opponent and score the goal, while defenders had to show great sprinting performance over 60 meters for coming back from phase of attack to the phase of defence.

\section{CONCLUSIONS}

Obtained results showed that our sample was homogenous according to their values on motor and functional tests performed in the study. Our study clearly showed that players at different playing positions did not differ in their conditioning abilities (except for the standing long jump). That homogeneity comes from equal training protocols and competitive periods, where preparedness on and off the field represents good sports form, which must be at the optimal level for best performance and achieving great sport results.

\section{REFERENCES}

Adhikari, A., \& Kumar, D. S. (1993). Physiological and physical evaluation of Indian national soccer squad. Hungarian Review of Sports Medicine, 34(4), 197-205.

Alzumaini, K. S., \& Fleck, S. J. (2008). Modification of the standing long jump test enhances ability to predict anaerobic performance. Journal of Strength Conditioning Research, 22(4), 1265-1272.

Bangsbo, J., Mohr, M., \& Krustrup, P. (2006). Physical and metabolic demands of training and match-play in the elite football player. Journal of Sports Science, 24(7), 665-674. doi: 10.1080/02640410500482529

Bangsbo, J., Norregaarg, L., \& Thorso, F. (1991). Activity profile of competition soccer. Canadian Journal of Sport Sciences, 16, 110-116.

Bangsbo, J. (1994 a). The physiology of soccer: With special reference to intense physical exercise. Acta Physiologica Scandinavica, 150(619), 1-156.

Bangsbo, J. (1994 b). The physiological demands of playing football. In B. Ekblom (Ed.), Football (Soccer) (pp. 43-58). London: IOC/Blackwell.

Barbero-Alvarez, J. C., Soto, V. M., Barbero-Alvarez, V., \& Granda-Vera, J. (2008). Match analysis and heart rate of futsal players during competition. Journal of Sports Science, 26, 63-73. doi: 10.1080/02640410701287289

Ben Abdelkrim, N., El Fazaa, S., \& El Ati, J. (2007). Time-motion analysis and physiological data of elite under-19-year-old basketball players during competition. British Journal of Sports Medicine, 41 (2), 69-75. PMCID: PMC2658931
Brahim, M. B., Bougatfa, R., \& Mohamed, A. (2013). Anthropometric and physical characteristics of Tunisian young soccer players. Advances in Physical Education, 3(3), 125-130. doi: 10.4236/ape.2013.33021

Gil, S. M., Gil, J., Ruiz, F., Irazusta, A., \& Irazusta, J. (2007). Physiological and anthropometric characteristics of young soccer players according to their playing position: Relevance for the selection process. Journal of Strength Conditioning Research, 21(2), 438-445. doi: 10.1519/R-19995.1

Iorsac, A. (2009). A comparison of physical characteristics among playing positions of junior football players. Transactions on Electronics and Communications (Scientific Bulletin of the Polytehnical University of Timisoara), 54(68), 21-27.

Janjić, A., Suzović, D., \& Janković, A. (2010). The motor abilities change of soccer players during the summer preparation period. Physical Culture, 64(1), 35-45.

Karavelioğlu, M. B. (2008). Investigation of the characteristics of amateur footballers' physical, physiological and psychomotor according to positions [Mevkilerine Göre Amatör Futbolcuların Fiziksel, Fizyolojik ve Psikomotor Özelliklerinin Araştırılması], (Master Thesis). Turkey: Dumlupınar University.

Kutlu, M., Yapıcı, H., Yoncalık, O., \& Celik, S. (2012). Comparison of a new test for agility and skill in soccer with other agility tests. Journal of Human Kinetics, 33, 143-150. doi: 10.2478/v10078-012-0053-1

Malina, R. M., Cumming, S. P., Morano, P. J., Barron, M., $\&$ Miller, S. J. (2005). Maturity status of youth football 
players: A noninvasive estimate. Medicine and Science in Sports Exercise, 37, 1044-1052. doi: 10.1249/01. mss.0000171622.45134.cb

Malina, R. M., Pena Reyes, M. E., Eisenmann, J. C., Horta, L., Rodrigues, J., \& Miller, R. (2000). Height, mass and skeletal maturity of elite Portuguese soccer players aged 11-16 years. Journal of Sports Sciences, 18, 685-693. PMID: 11043894

Pivovarniček, P., Pupiš, M., Tonhauzerova, S., \& Tokarova, M. (2014). A level of running speed of elite young soccer players at different positions. Acta Kinesiologica, 8(1), 21-26.

Rienzi, E., Drust, B., Reilly, T., Carter, J. E., \& Martin, A. (2000). Investigation of anthropometric and work-rate profiles of elite South American international soccer players. Journal of Sports Medicine and Physical Fitness, 40, 162-169. PMID: 11034438

Rocha, M. S. L. (1975). Bone weight of Brazilians both sexes from 17 to 25 years old. Aquino de Anatomia e Antropologia, 1, 445-451.

Sporiš, G., Ružić, L., \& Leko, G. (2008). Effects of a new experimental training program on $\mathrm{VO}_{2} \max$ and running performance. Journal of Sports Medicine and Physical Fitness, 48(2), 158-165.

Zalai, D., Bobak, P., Csaki, I., Hamar, P., Myrer, J. W., Mitchell, U. H., \& Johnson, A. W. (2015). Motor skills, anthropometrical characteristics and functional movement in elite young soccer players. Journal of Exercise, Sports \& Orthopaedics, 2(1), 1-7. 